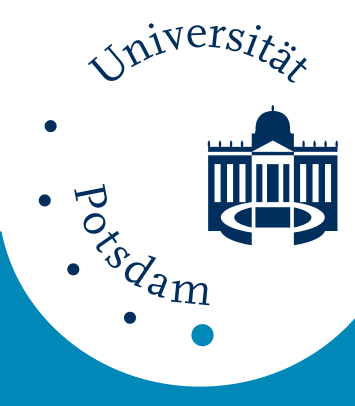

Universität Potsdam

Rainer Schultze, Matthias Lemke

Hans-Gerd Löhmannsröben

\title{
Laser-induced fluorescence (LIF) spectro- scopy for the in situ analysis of petroleum product-contaminated soils
}

first published in:

Laser in environmental and life sciences : modern analytical methods /

Peter Hering; Jan P. Lay, Sandra Stry(Eds.). Berlin u.a. : Springer , 2004, p. $79-98$

ISBN 978-3-540-40260-2

Postprint published at the institutional repository of Potsdam University:

In: Postprints der Universität Potsdam :

Mathematisch-Naturwissenschaftliche Reihe ; 9

http://opus.kobv.de/ubp/volltexte/2007/1227/

http://nbn-resolving.de/urn:nbn:de:kobv:517-opus-12271

Postprints der Universität Potsdam

Mathematisch-Naturwissenschaftliche Reihe ; 9 


\title{
5 Laser-Induced Fluorescence (LIF) Spectroscopy for the In Situ Analysis of Petroleum Product-Contaminated Soils
}

\author{
R.H. Schultze, M. Lemke and H.-G. Löhmannsröben
}

\subsection{Introduction}

Laser-induced fluorescence (LIF) spectroscopy is of great importance for environmental monitoring. Besides outstanding sensitivity and good selectivity, particular advantages of the LIF technique include the capabilities for in situ analysis and remote sensing. The major advantage of in situ LIF measurements is the lack of sampling and clean-up procedures preceding the analysis. Such procedures are error-prone, time consuming and expensive. The contamination of water or soil with petroleum products (oils) represents a major environmental risk. Since most petroleum products exhibit distinct native fluorescence it is promising to apply LIF analysis to the detection and characterization of oils in environmental compartments. The LIF investigation of oil-polluted waters with LIDAR and fiber optical sensing techniques is well advanced and appropriate instrumentation is commercially available. The employment of fluorescence techniques for in situ analysis of soil contaminations has received considerable attention only during the last decade. The combination of LIF instrumentation with geotechnical drilling equipment for real-time subsurface detection of oil pollutions, as pioneered by Lieberman et al. (Lieberman 1990), and field demonstrations have recently been described in detail in technology reviews and a monograph (Hart 1997, Lieberman 1998, Balshaw-Biddle 2000). Importantly, LIF-based techniques find increasing regulatory acceptance and have been verified as field screening methods for petroleum products by the US Environmental Protection Agency (US-EPA). For assessment and control of the environmental damage imposed in Kuwait during the Gulf War LIF investigations play an important role in what may become the "biggest environmental remediation project ever attempted" (Shouse 2001, Quinn 1995). In Germany, various aspects of LIF analysis of soils have been addressed in works of, among others, Niessner et al., Schade et al., Marowsky et al., Zimmermann and Lucht (Baumann 2000, Schade 1996, Marowsky 2001, Zimmermann 1997, and references therein), as well as by our group (Löhmannsröben 1996, 1997, 1999, 2000). 
805 Laser-Induced Fluorescence (LIF) Spectroscopy for the In Situ Analysis of Petroleum Product-Contaminated Soils

As for most other analytical techniques, calibration is essential for quantitative LIF analysis. It is therefore important to consider the signal/concentration-relationship. Under appropriate experimental conditions the measured LIF signal intensities $I_{\mathrm{F}}\left(\lambda_{\mathrm{em}}\right)$ at the emission wavelengths $\lambda_{\mathrm{em}}$ can approximately be described by the following general equation:

$$
I_{\mathrm{F}}\left(\lambda_{\mathrm{em}}\right)=\text { const. } I_{0}\left(\lambda_{\mathrm{ex}}\right) \varepsilon^{*}\left(\lambda_{\mathrm{ex}}\right) \eta_{\mathrm{F}}\left(\lambda_{\mathrm{ex}}\right) f(M) c
$$

Here, the term const. includes constant apparative and experimental parameters such as detection geometry, detector sensitivity, etc., $I_{0}\left(\lambda_{\text {ex }}\right)$ is the excitation intensity at the excitation wavelength $\lambda_{\text {ex }}, \varepsilon^{*}\left(\lambda_{\text {ex }}\right)$ and $\eta_{\mathrm{F}}\left(\lambda_{\text {ex }}\right)$ are effective extinction coefficients and fluorescence efficiencies, respectively, and $c$ is the concentration of the analyte, i. e. the oil. Since petroleum products are complex multicomponent mixtures both $\varepsilon^{*}\left(\lambda_{\mathrm{ex}}\right)$ and $\eta_{\mathrm{F}}\left(\lambda_{\mathrm{ex}}\right)$ are excitation wavelength-dependent and cannot directly be related to molecular parameters. The influence of various matrix parameters $(M)$ on the LIF signal is symbolized by heuristic introduction of the function $f(M)$. Without this term, Equation 5.1 is derived from the Lambert-Beer law under the condition of small overall absorbance $A\left(\lambda_{\text {ex }}\right)$ over the optical interaction length $d$ :

$$
A\left(\lambda_{\text {ex }}\right)=\varepsilon^{*}\left(\lambda_{\text {ex }}\right) c d<<1
$$

For one given analyte, with the excitation conditions kept constant, Equation 5.1 can be simplified to a calibration function which expresses the linear relationship between LIF signal intensity and analyte concentration:

$$
I_{\mathrm{F}}\left(\lambda_{\mathrm{em}}\right)=m(M) c
$$

The slope of the calibration function $m(M)$ is a direct measure of the detection sensitivity and thus an important analytical benchmark. Comparison of Equations 5.1 and 5.3 shows that $m(M)$ depends both on matrix parameters and on analyte properties, namely on the product $\left[\varepsilon^{*}\left(\lambda_{\mathrm{ex}}\right) \times \eta_{\mathrm{F}}\left(\lambda_{\mathrm{ex}}\right)\right]$. As to matrix parameters, we have previously shown that for different Diesel fuel-spiked soils with varying optical properties it is important to take into account the soils' diffuse reflectances $(R)$ in the spectral range of oil emission (Löhmannsröben 1999). The current report will focus on photophysical properties of the oils, i. e. on the expected direct proportionality between $m(M)$ and $\left[\varepsilon^{*}\left(\lambda_{\text {ex }}\right) \times \eta_{\mathrm{F}}\left(\lambda_{\text {ex }}\right)\right]$. It is our aim to derive an understanding of the LIF calibration behavior by connecting oil properties with LIF measurements of oil-spiked soils as laboratory reference (LR) materials. This 
work is thus part of our attempt to employ laser-based techniques for qualitative and quantitative in situ analysis of oil-contaminated soils. Based on the knowledge of the photophysical properties of oils as analytes and of the optical properties of soils as matrices, it is our strategy to use LR and certified reference (CR) materials to make way from the investigation of spiked and real-world samples in the laboratory towards on site field applications.

\subsection{Experimental Techniques}

\subsubsection{The LIF demonstrator unit}

In the course of a research project, a mobile LIF spectrometer was developed (Fig. 5.1). As a first step, a demonstrator unit was set up at the University of Erlangen-Nürnberg. The unit used a $\mathrm{N}_{2}$-Laser (MSG 500, LTB Berlin, pulse energy ca. $400 \mu \mathrm{J}$ at $337 \mathrm{~nm}$, pulse duration ca. $500 \mathrm{ps}$ ) as excitation light source. For detection, a photomultiplier (Hamamatsu R 2496) in combination with a monochromator (Acton Research, Spectra-Pro 275) was employed. A cut-off filter (GG 368, Schott) was placed in front of the monochromator. Data acquisition was performed by a 14 bit AD/DA-conversion card (Decision Computer Inc.). The card was later replaced by a Keithley DAS 1601 Data Aquisition Board. LIF measurements from soil surfaces were performed using a simple sensor head with bifurcated fiber bundles (quartz fibers with ca. $100 \mu \mathrm{m}$ diameter for excitation and detection) connected to a plain circular metal plate. This resulted in an anti-parallel orientation of excitation and emission optical paths $\left(180^{\circ}\right.$ geometry). Towards the soil surfaces, the fiber was protected by a $3 \mathrm{~mm}$ quartz glass window. At the soil remediation plant additional subsurface measurements were performed in soil heaps using a metal lancet equipped with bifurcated quartz fiber bundles and a sapphire window. 

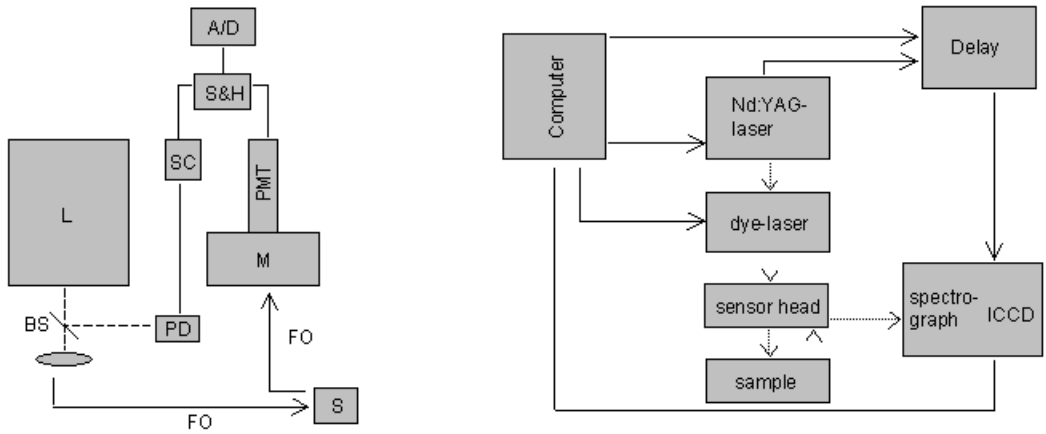

Fig. 5.1. Schematic representation of the LIF spectrometers. Left: LIF demonstrator unit (L: $\mathrm{N}_{2}$-laser, BS: beam splitter, FO: fiber optics, S: sample, M: monochromator, PMT: photomultiplier, PD: photodiode, SC: signal converter, S\&H: sample and hold amplifier, A/D: analog/digital converter), right: mobile LIF spectrometer OPTIMOS.

\subsubsection{The mobile LIF spectrometer OPTIMOS}

Based on the experiences with the demonstrator unit, a mobile LIF system was designed and manufactured at Optimare GmbH. This device, called OPTIMOS (oil pollution transportable independent monitoring system), includes a diode laser-pumped Nd:YAG-laser (B.M.Industries, pulse energies ca. $5 \mathrm{~mJ}$ at $355 \mathrm{~nm}$ and $700 \mu \mathrm{J}$ at $266 \mathrm{~nm}$, pulse duration ca. $10 \mathrm{~ns}$ ) as excitation source (Fig. 5.1). The OPTIMOS can additionally be equipped with a custom designed dye laser. An intensified CCD camera (Andor, ICCD DH501-18, 1024×128 pixels, minimum gate width less than $5 \mathrm{~ns}$ ) in combination with a spectrograph (LOT-Oriel, MS125, F/3.7) was used as detection system. For the measurements of the real-world soil samples in the laboratory, the OPTIMOS was operated at an excitation wavelength of $355 \mathrm{~nm}$ with a cut-off filter GG 385 (Schott) to reduce backscattered excitation light. For the experiments at the gravel pit, a flash lamp-pumped Nd:YAG laser (Minilite 2, Continuum) with $266 \mathrm{~nm}$ excitation (cut-off filter GG 368) was chosen. To demonstrate the capability of real-time subsurface measurements, the OPTIMOS was also combined with a truck-based cone penetrometer and directpush measurements were performed at the pit site using a specifically designed penetrometer tip. 


\subsubsection{Investigated petroleum products and soil samples}

As petroleum products, 10 different oils, provided by the Wilhelmshavener Raffineriegesellschaft, were investigated. The samples included various petroleum products (distillates and reformates) as well as crude oils of different provenience (see Table 5.1). For absorption measurements (Perkin Elmer, Lambda 2, slit widths $2 \mathrm{~nm}$ ) of the oils diluted with cyclohexane, the concentrations were ca. 1, $5,100 \mathrm{~g} / \mathrm{L}$ for the crude oils, distillates and reformates, respectively. Emission properties of dilute and neat oils were investigated with the LIF systems $\left(180^{\circ}\right.$ geometry) and a conventional fluorescence spectrometer (Perkin Elmer, LS50 with 1P28 photomultiplier, slit widths $2.5 \mathrm{~nm}, 90^{\circ}$ geometry).

Table 5.1 Photophysical and calibration data of the petroleum products

\begin{tabular}{|c|c|c|c|c|c|c|c|c|}
\hline \multirow[b]{2}{*}{$\underset{\text { (a) }}{\text { Oil }}$} & \multicolumn{2}{|c|}{ Absorption } & \multicolumn{2}{|c|}{ Fluorescence } & \multicolumn{4}{|c|}{ Calibration } \\
\hline & $\begin{array}{l}\varepsilon^{*(b)} \\
\mathrm{L} \mathrm{g}^{-1} \mathrm{~cm}^{-1}\end{array}$ & $\begin{array}{l}U^{(\mathrm{c})} \\
\mathrm{cm}^{-1}\end{array}$ & $\begin{array}{l}\eta_{\mathrm{F}}{ }^{(\mathrm{d})} \\
\text { (dil.) }\end{array}$ & $\begin{array}{l}\eta_{F}{ }^{(d)} \\
\text { (neat) }\end{array}$ & $m^{\text {Qua }}$ & $\begin{array}{l}\text { Sand } \\
\text { LOD } \\
\text { ppm }\end{array}$ & $m^{(\mathrm{e})}$ & $\begin{array}{c}\text { h Soil } \\
\text { LOD } \\
\text { (f) } \\
\text { ppm }\end{array}$ \\
\hline Df 1 & 0.039 & 3.2 & 0.50 & $1.0^{*}$ & 1.4 & 600 & 0.4 & $>2,000$ \\
\hline Df 2 & 0.012 & 2.4 & 0.58 & 0.65 & n.d. ${ }^{(\mathrm{g})}$ & n.d. & n.d. & n.d. \\
\hline Fo & 0.076 & 3.8 & 0.74 & 0.91 & 16 & 50 & 4 & 530 \\
\hline Gas 1 & 0.005 & 5.3 & 0.67 & 0.67 & n.d. ${ }^{(g)}$ & n.d. & n.d. & n.d. \\
\hline Gas 2 & 0.013 & 3.5 & 0,70 & 0.78 & 7.8 & 110 & 0.6 & $>2,000$ \\
\hline Gcr & 3.5 & 10.8 & 0.71 & 0.07 & 36 & $\approx 23$ & 6 & 340 \\
\hline Icr & 3.2 & 10.5 & 0.52 & 0.06 & 62 & $\approx 13$ & 12 & 190 \\
\hline Lcr & 1.8 & 11.8 & 0.58 & 0.15 & n.d..$^{(g)}$ & n.d. & n.d. & n.d. \\
\hline Acr & 1.5 & 8.3 & $1.0 *$ & 0.54 & 220 & $\approx 4$ & 23 & 100 \\
\hline NScr & 0.9 & 9.0 & 0.79 & 0.27 & 110 & $\approx 8$ & 34 & 60 \\
\hline
\end{tabular}

${ }^{a}$ Df, Diesel fuel; Fo, fuel oil; Gas, gasoline; Gcr, German crude; Icr, Iranian crude; Lcr, Libyan crude; Acr, Algerian crude; NScr, North Sea crude, ${ }^{b}$ effective extinction coefficients measured for dilute oils in cyclohexane at $\lambda_{\mathrm{ex}}=337 \mathrm{~nm},{ }^{\mathrm{c}}$ Urbach decay width obtained from a linear fit of logarithmic dilute oil absorbances versus the photon energy (cf. Equation 5.3) in $10^{3} \mathrm{~cm}^{-1},{ }^{d}$ fluorescence efficiencies were measured with $\lambda_{\mathrm{ex}}=337 \mathrm{~nm}$ $\left(180^{\circ}\right.$ geometry) and are given relative to the oils (marked by an asterisk) showing the highest intensities, ${ }^{\mathrm{e}}$ slopes of the calibration functions (cf. Equation 5.2, in $10^{3}$ rel. units/ppm, for crude oils on quartz sand determined in low concentration ranges) as measured with the OPTIMOS unit $\left(\lambda_{\mathrm{ex}}=355 \mathrm{~nm}\right),{ }^{\mathrm{f}}$ detection limits were calculated from the ratios of the threefold standard deviations of blanks (uncontaminated soils, 10 replicate measurements) and $m,{ }^{\mathrm{g}}$ n.d.: not determined.

The emission spectra obtained under $180^{\circ}$-geometry were superimposed by a strong scattering signal from reflections on the cuvettes surfaces which was eliminated by subtraction of a cyclohexane reference spectrum. Emission measurements were not quantum-corrected. Standard $1 \mathrm{~cm} \times 1 \mathrm{~cm}$ cuvettes (Helma) were used for the absorption and emission experiments. For the investigation of oil- 
spiked LR soils, two different materials were used, namely a commercially available quartz sand (Lugato Chemie Hamburg) and a soil taken from an $\mathrm{A}_{\mathrm{h}}$-horizon. The $A_{h}$-soil, a pseudogley podsol, was provided and characterized by the Institute of Geology and Mineralogy of the University Erlangen-Nürnberg. For laboratory investigations, $20 \mathrm{~g}$ of soil with oil contents of $250-5,000 \mathrm{ppm}$, as determined gravimetrically, were used. The samples were mixed by stirring with a spatula for 5 min without addition of any solvent.

In addition to the LR materials, real-world contaminated soil and waste samples were investigated. These samples were obtained from Umweltschutz Nord (Ganderkesee) and the University of Applied Sciences in Wilhelmshaven. The soil samples, which were taken at five different locations, were subsequently dried and ground in the laboratory. The waste samples were also taken from various locations and consisted of completely different materials, e. g., natural soils, slurry, rubble, industrial deposits etc. Umweltschutz Nord analyzed the soils and wastes for their total petroleum hydrocarbon (TPH) contents with IR-spectroscopy as reference analysis according to the German DIN 38409-H18 (corresponding to USEPA method 418.1). TPH contents of the real-world samples ranged from $<100$ ppm up to ca. 20,000 ppm.

\subsection{Results and Discussion}

\subsubsection{Photophysical properties of the petroleum products}

Absorption spectra of some of the oils diluted in cyclohexane are shown in Figure 5.2, and extinction coefficients at one laser excitation wavelength $\left(\lambda_{\mathrm{ex}}=337 \mathrm{~nm}\right)$ are given in Table 5.1.

As is characteristic for such complex multi-component mixtures, the petroleum products show a structureless absorption behavior with a strong increase from low absorbances in the NIR to strong absorbances in the UV spectral region. Only in the spectra of the gasolines, absorption bands at $360 \mathrm{~nm}$ and $380 \mathrm{~nm}$ can be observed (inset in the left part of Figure 5.2). Considering the oil classes, it is obvious that the colored crude oils exhibit the strongest absorbances. At 337 and $420 \mathrm{~nm}$ (data not given), the effective extinction coefficients $\varepsilon^{*}\left(\lambda_{\text {ex }}\right)$ of the oils vary by about 2 and 3.5 orders of magnitude, respectively. The absolute values of $\varepsilon^{*}\left(\lambda_{\text {ex }}\right)$ can be regarded as typical for the oils and are consistent with earlier analytical determinations (Löhmannsröben 1996, 1997).

Extended long-wavelength absorption tails are often described in terms of the so-called Urbach phenomenology. Originally, this concept was developed for the analysis of alkali halide absorption, and later successfully extended to evaluate absorption behavior of such diverse materials as liquid water, glasses, organic dyes, amorphous semiconductors and even solvated electrons. 

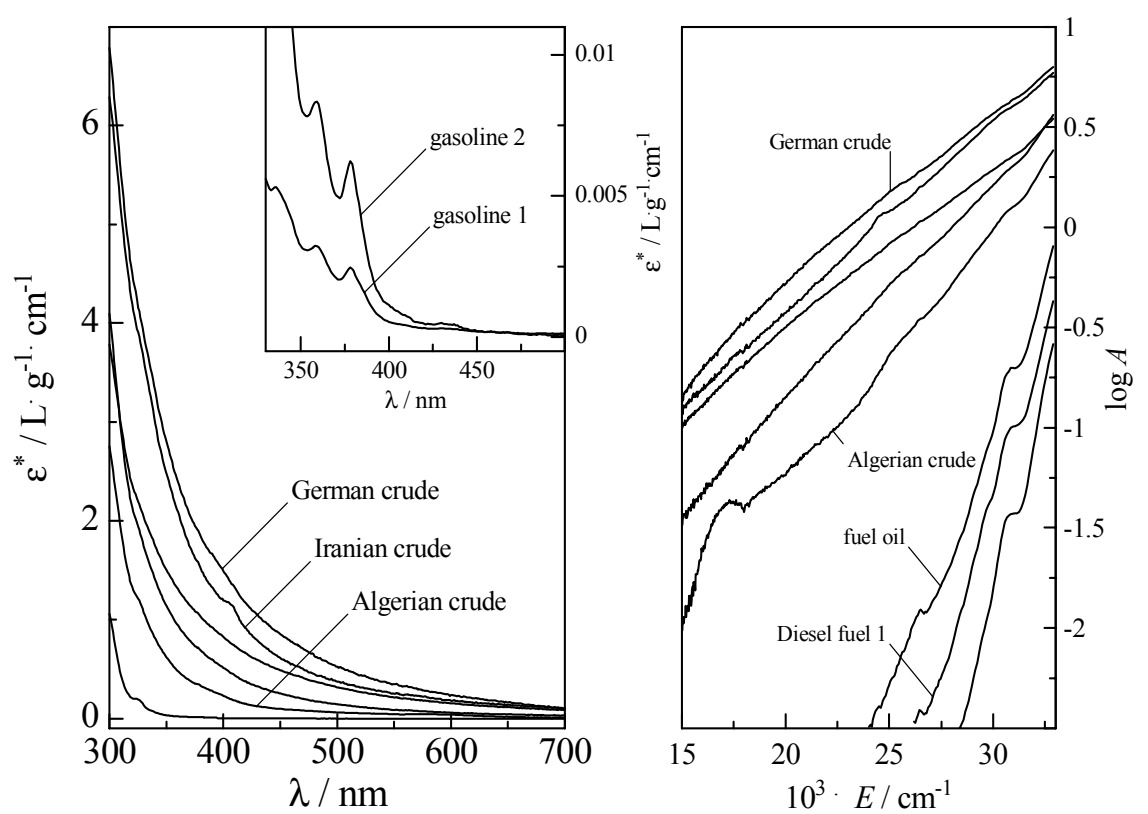

Fig. 5.2. Absorption spectra (left) and Urbach representation (right) of selected dilute oils. Left: Figure of the extinction coefficient plotted against the wavelength. The absorbance $A$ refers to oil concentrations of $0.1 \mathrm{~g} \cdot \mathrm{L}^{-1} \cdot \mathrm{cm}^{-1}$ and $1 \mathrm{~cm}$ cuvettes.

It is based on the idea that a thermally or structurally disordered system with a distribution of absorption sites can produce an absorption profile which depends exponentially on the photon energy $E$ (the Urbach rule):

$$
A(E) \propto \exp (E / U)
$$

Here, the so-called Urbach decay width $U$ is an energy term consisting of thermal and structural elements. We have interpreted the absorption spectra of humic substances, which are important constituents of dissolved organic materials and ubiquitous in natural waters and soils, with the simple Urbach Ansatz (Illenseer 1999). Mullins et al. were first to discuss the absorption spectra of different crude oils and asphaltenes in the framework of the Urbach theory (Mullins, Zhu 1992). The dependence of $\log A$ vs. $E$ for some of our oils is shown in the right part of Figure 5.2. Despite some residual spectral features overlaid, the expected linearity is found, and it can be concluded that the long-wavelength absorption tails are consistent with the Urbach rule. The other oils exhibited similar behavior. The Urbach decay widths calculated from these spectra are in the range $U=2,400-12,800 \mathrm{~cm}^{-1}$, which is in complete agreement with the results reported by Mullins et al. for different crude oils (Mullins et al. 1992). It is notable that these values of $U$ are much larger than the thermal energy at room temperature $\left(\mathrm{k} T=207 \mathrm{~cm}^{-1}\right)$. This is indicative of components with high structural disorder. It 
865 Laser-Induced Fluorescence (LIF) Spectroscopy for the In Situ Analysis of Petroleum Product-Contaminated Soils

is reasonable that such constituents are predominantly present in the crude oils which are expected to contain biogenic macromolecules and polymers. Further investigations are necessary to elucidate the potential of the parameter $U$ to characterize and understand petroleum product properties.

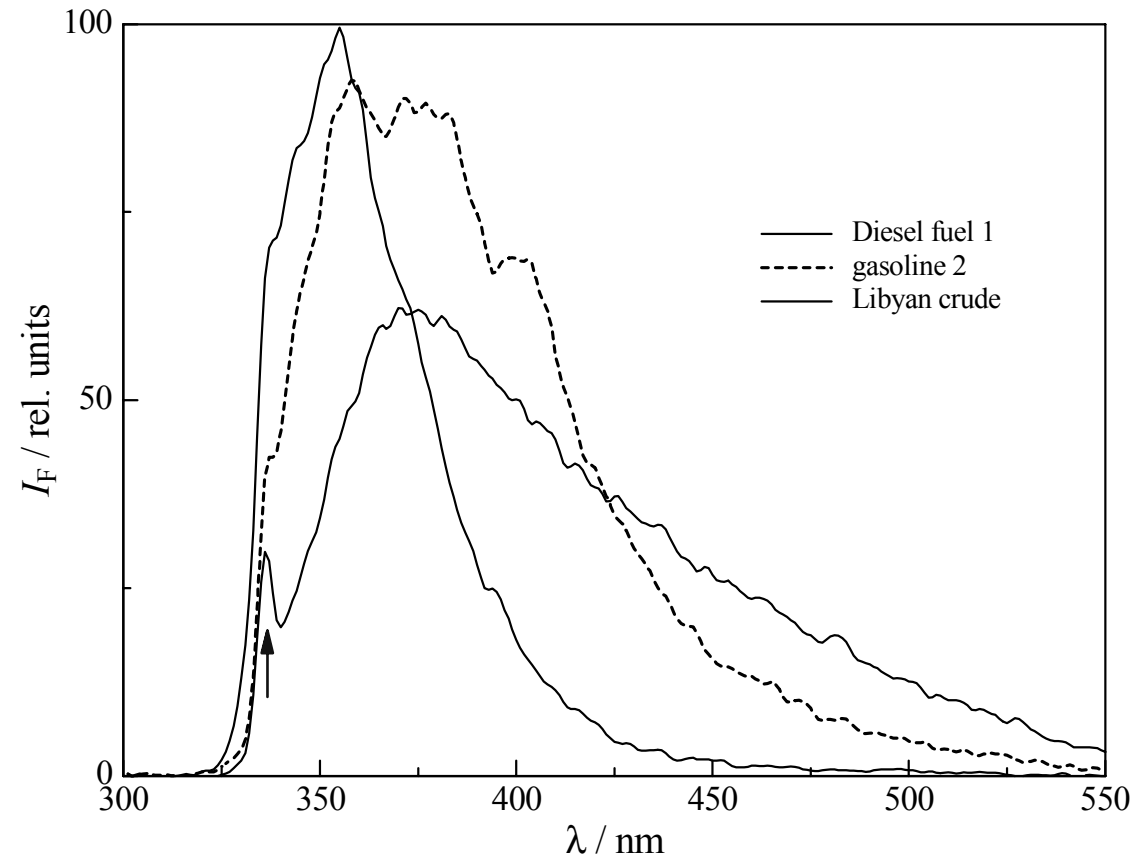

Fig. 5.3. Emission spectra of three dilute oils. The measurements were performed in $1 \mathrm{~cm}$ cuvettes with the conventional fluorescence spectrometer (Perkin Elmer LS50, $\lambda_{\mathrm{ex}}=337 \mathrm{~nm}$, absorbance ca. 0.1). The arrow marks residual stray light. 
The fluorescence spectra of dilute and neat oils were recorded with an excitation wavelength of $\lambda_{\mathrm{ex}}=337 \mathrm{~nm}$. Typical spectra of dilute oils are shown in Figure 5.3. The distillates and the crude oils show broad structureless emission spectra with maxima at $\lambda_{\mathrm{em}} \approx 355 \mathrm{~nm}$ (distillates), resp. $\lambda_{\mathrm{em}} \approx 370-380 \mathrm{~nm}$ (crude oils). Only for the reformates more structurized emission spectra with maxima at $\lambda_{\mathrm{em}} \approx 360,380$ and $410 \mathrm{~nm}$ were observed. In Figure 5.4, the fluorescence spectra of dilute and neat Algerian crude oil and fuel oil are compared as representative examples. For all neat oils a red spectral shift of the emission with respect to the dilute oils was observed. In comparison to the dilute oils, the fluorescence signal intensities $I_{\mathrm{F}}\left(\lambda_{\mathrm{em}}\right)$ were lower for the neat crude oils, but larger for the distillates and reformates. In order to obtain relative fluorescence efficiencies $\eta_{\mathrm{F}}\left(\lambda_{\mathrm{ex}}\right)$ of the dilute oils, samples were prepared with approximately the same absorbance at the excitation wavelength $(A \approx 0.1$ at $337 \mathrm{~nm})$.
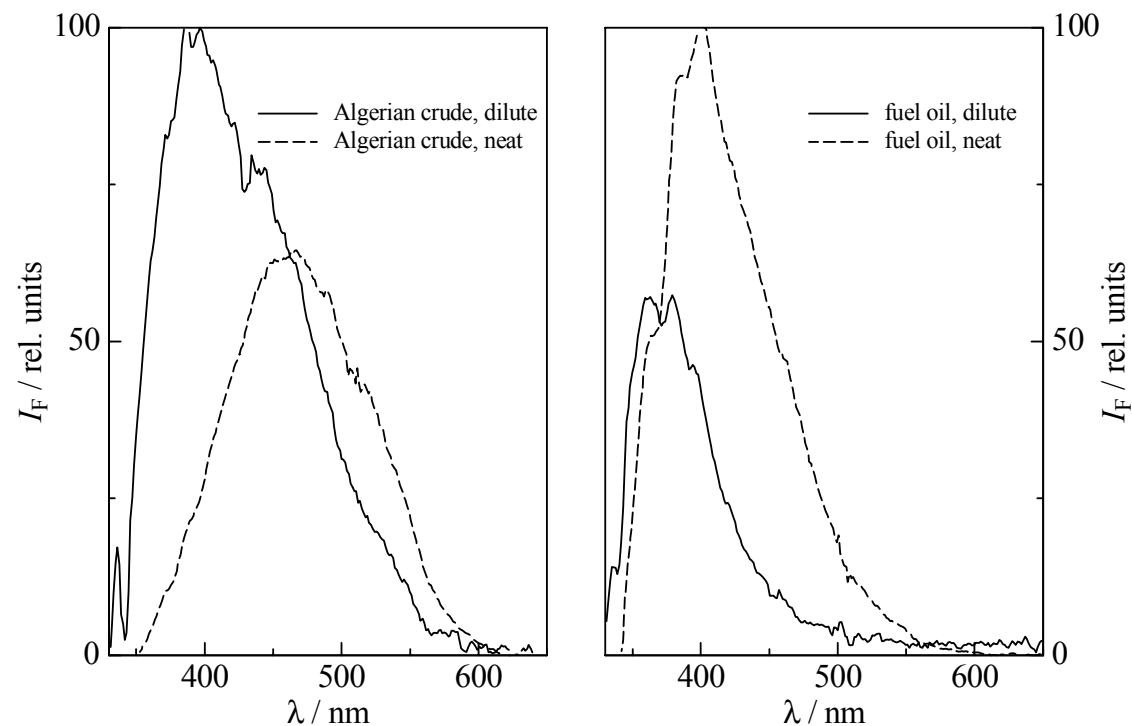

Fig. 5.4. Comparison of dilute and neat oil fluorescence spectra for Algerian crude (left) and fuel oil (right).

For the $180^{\circ}$ excitation geometry employed we also assume same excitation conditions among all the neat oils, where the high absorbances garantee complete absorption of the excitation light within a very small volume. Therefore, relative fluorescence efficiencies were simply determined by integration of the emission spectra of dilute and neat oils. For the dilute oils under consideration the $\eta_{\mathrm{F}}\left(\lambda_{\mathrm{ex}}\right)$ values differ not more than by a factor of 2 , and no systematic variation among the oil classes is evident. This is in agreement with our earlier investigations, in which absolute values of $\eta_{\mathrm{F}}\left(\lambda_{\text {ex }}\right)$ ranging from 0.35 for a Diesel fuel to 0.52 for Brent crude oil were determined (diluted in cyclohexane, under $\mathrm{N}_{2}, \lambda_{\mathrm{ex}} 337 \mathrm{~nm}$ ) (Löh- 
mannsröben et al. 1997). In contrast, the fluorescence efficiencies of the neat crude oils are approximately one order of magnitude lower than those of the neat reformates and distillates. These results indicate the clear difference between fluorescence properties of dilute and neat oils, i. e a distinct concentration dependence of fluorescence spectral properties and efficiencies. Such a behavior can be caused by fluorescence quenching processes between different oil components, as shown, e.g., for benzene and naphthalene (Lieberman 1998), or in time-resolved fluorescence measurements of crude oils in different concentrations (Wang 1994). Also, reabsorption of fluorescence photons by the long-tailing absorption bands, the socalled inner filter effect, has to be considered. While it is plausible to consider neat oil characteristics as "native" oil properties, it is also clear that particularly reabsorption will be much lower in dilute oils. It is therefore instructive to normalize neat oil- with respect to dilute oil- fluorescence efficiencies and to relate this ratio with the oils' effective extinction coefficients. Figure 5.5 shows an approximately logarithmic correlation between $\left[\eta_{\mathrm{F}}(\right.$ neat $) / \eta_{\mathrm{F}}($ dilute $\left.)\right]$ and $\varepsilon^{*}$, which suggests that the reduced fluorescence capabilities of crude oils are mainly due to the inner filter effect.

Fig. 5.5. Semi-logarithmic representation of the ratio of the relative fluorescence efficiencies of neat and dilute oils vs. effective extinction coefficients at $337 \mathrm{~nm}$.

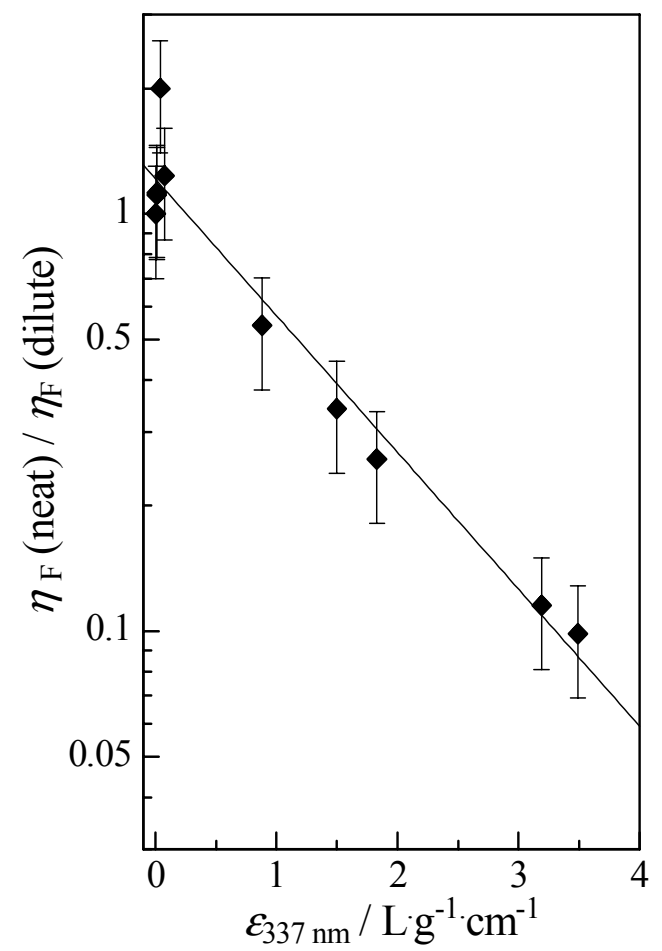




\subsubsection{LIF spectroscopic investigations of oil-spiked samples}

LIF calibration measurements were performed with oil-spiked quartz sand and $A_{h}$ soil as LR materials. For practical purposes it is convenient to employ the backscattered excitation light, detected in the second diffraction order $(710 \mathrm{~nm})$, for normalization of the LIF signals. This can be used to correct for different experimental settings, as e. g. detection sensitivities (Fig. 5.6), or for strongly varying soil properties (see below). If not mentioned otherwise all LIF measurements of LR and real-world soil presented below were corrected in such a way. LIF spectra measured for various concentrations of Algerian crude oil on quartz sand, and the concentration dependence of the integrated LIF signals together with the calibration function $I_{\mathrm{F}}$ VS. $c$, are shown in Figure 5.6 (middle and right part).
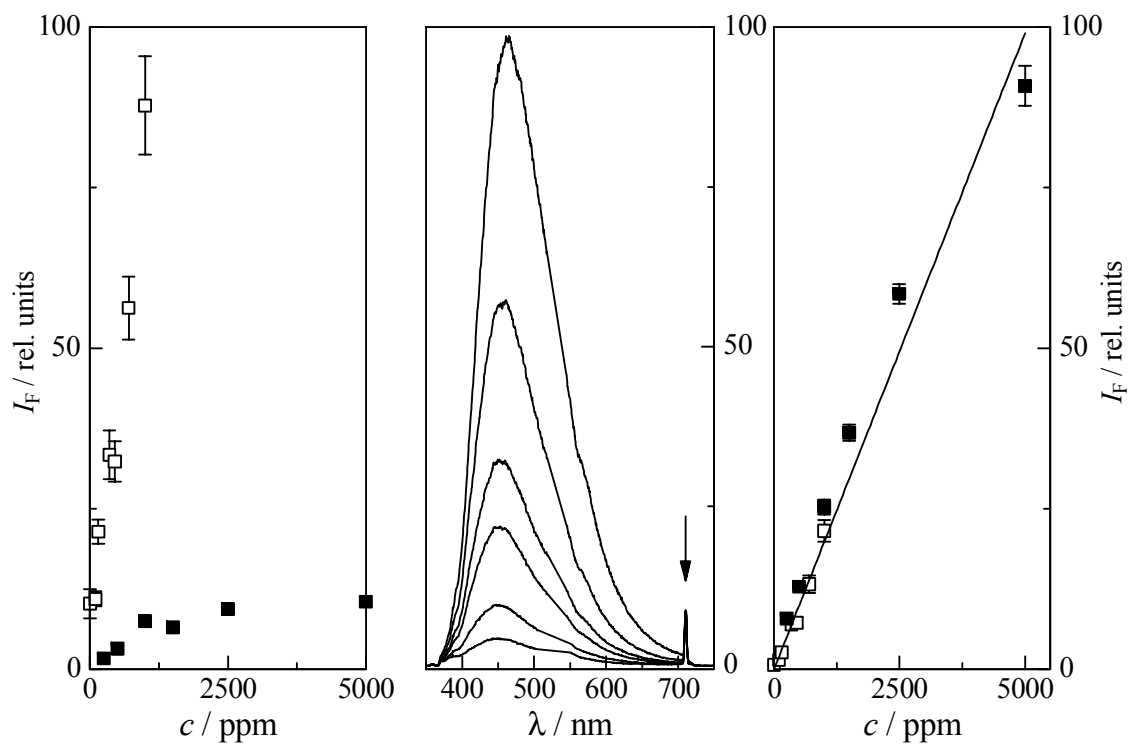

Fig. 5.6. LIF intensities (left) and spectra (middle) of Algerian crude oil in a concentration range of $250-5,000 \mathrm{ppm}$ on quartz sand as measured with the OPTIMOS $\left(\lambda_{\text {ex }}=355 \mathrm{~nm}\right)$. In the left, results obtained with two different gains of the ICCD-camera are displayed. The spectra in the middle were normalized to the intensity of residual laser stray light (arrow, detected in second diffraction order at $710 \mathrm{~nm}$ ). Right: Calibration function obtained with the normalized fluorescence intensities.

More examples of the calibration functions obtained are shown in Figure 5.7. From these results the following qualitative observations can be made: (i) Most of the calibration measurements yielded the expected linear relationship between the integrated LIF signal intensities $I_{\mathrm{F}}$ and oil concentrations $c$ (cf. Equation 5.1). With quartz sand as matrix for the crude oils a nonlinear behavior at higher concentrations was observed. This is due to changes of the quartz sand optic properties (coloration) with high oil dosages. In these cases, the slopes of the calibration functions were determined in low concentrations ranges $(c<2,000 \mathrm{ppm})$. (ii) For 
905 Laser-Induced Fluorescence (LIF) Spectroscopy for the In Situ Analysis of Petroleum Product-Contaminated Soils

the $A_{h}$ soil as matrix, the calibration functions are significantly flatter than for quartz sand. This indicates the direct influence of the lower reflectance $R$ of the darker soil. It is notable that the non-spiked $\mathrm{A}_{\mathrm{h}}$ soil produced a significant background signal, which presumably stems from fluorescence of soil organic matter. The analytical parameters obtained, namely the slopes of the calibration function $m$ (sensitivities) and the detection limits (LOD), are also included in Table 5.1. It can be seen that for the different oil types the sensitivities differ strongly, varying, e. g., on quartz sand from 1.4 to 220 rel. units/ppm for Diesel fuel 1 and North Sea crude oil, respectively. With two exceptions (see below), the detection limits determined range from $\mathrm{LOD} \approx 4-23 \mathrm{ppm}$ for the crude oils on quartz sand to ca. $500-600 \mathrm{ppm}$ for Diesel fuel 1 on quartz sand and fuel oil on the $\mathrm{A}_{\mathrm{h}}$ soil.
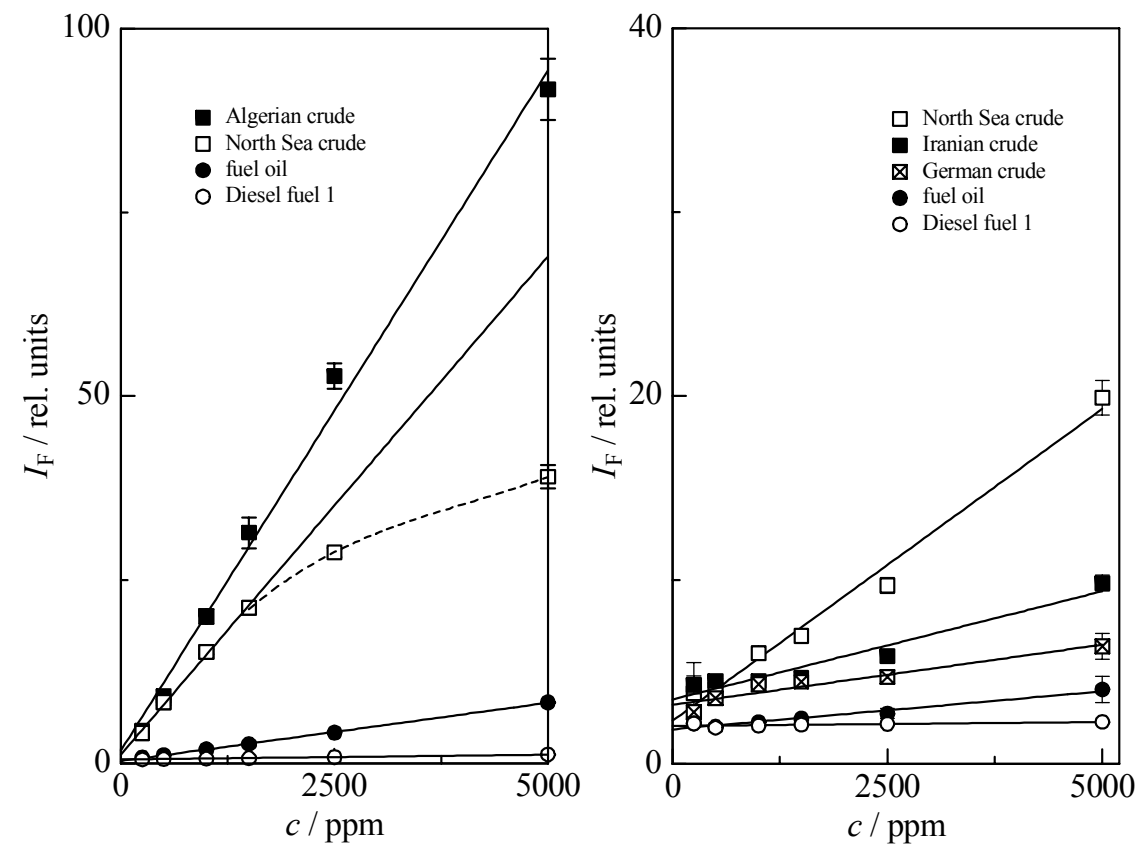

Fig. 5.7. Calibration functions of selected oils on quartz sand (left) and the $A_{h}$ soil (right) as measured with the OPTIMOS $\left(\lambda_{\mathrm{ex}}=355 \mathrm{~nm}\right)$. Also shown in the left part is an example of the non-linear response (North Sea crude oil) and the extrapolated line from the linear initial part at low concentrations.

These findings are in accordance with earlier results from the investigation of LR materials (Löhmannsröben 1999) and from subsurface field screening measurements (Liebermann 1998). Because of their low absorbances with respect to a dark matrix, Diesel fuel 1 and gasoline 2 on the $A_{h}$ soil represent examples for which the sensitivities are so low $(\mathrm{m}<0.6 \mathrm{rel}$. units $/ \mathrm{ppm})$ that only lower boundaries of the LOD values can given. Generally, for the LIF analysis of reformates 
and distillates the usage of the frequency-quadrupled emission of Nd:YAG lasers $\left(\lambda_{\mathrm{ex}}=266 \mathrm{~nm}\right)$ yields much better results.

The highly varying calibration behavior of the oils under investigation can be traced back to their absorption and emission properties, viz. to the product of effective extinction coefficients $\varepsilon^{*}$ and relative fluorescence efficiencies $\eta_{\mathrm{F}}$ (cf. Equation 5.1). Since we have determined $\eta_{\mathrm{F}}$ with an excitation at $\lambda_{\mathrm{ex}}=337 \mathrm{~nm}$, also $\varepsilon^{*}(337 \mathrm{~nm})$ is employed in the following. For neat and dilute oils, plots of the products $\left(\varepsilon^{*} \times \eta_{\mathrm{F}}\right)$ vs. $m$ determined on quartz sand are shown in Figure 5.8 (left and right parts). Obviously, introduction of the dilute oil properties does not yield a picture consistent with Equation 5.1. On the contrary, if the neat oil properties are employed the data suggest the expected direct proportionality between $\left(\varepsilon^{*} \times \eta_{\mathrm{F}}\right)$ and $m$ (left part of Figure 5.8). The situation is completely analogous for the sensitivities determined on the $A_{h}$ soil. The results presented in Figure 5.8 therefore provide a convincing illustration that the neat oil properties are the analyte parameters relevant for the calibration behavior of the oils.
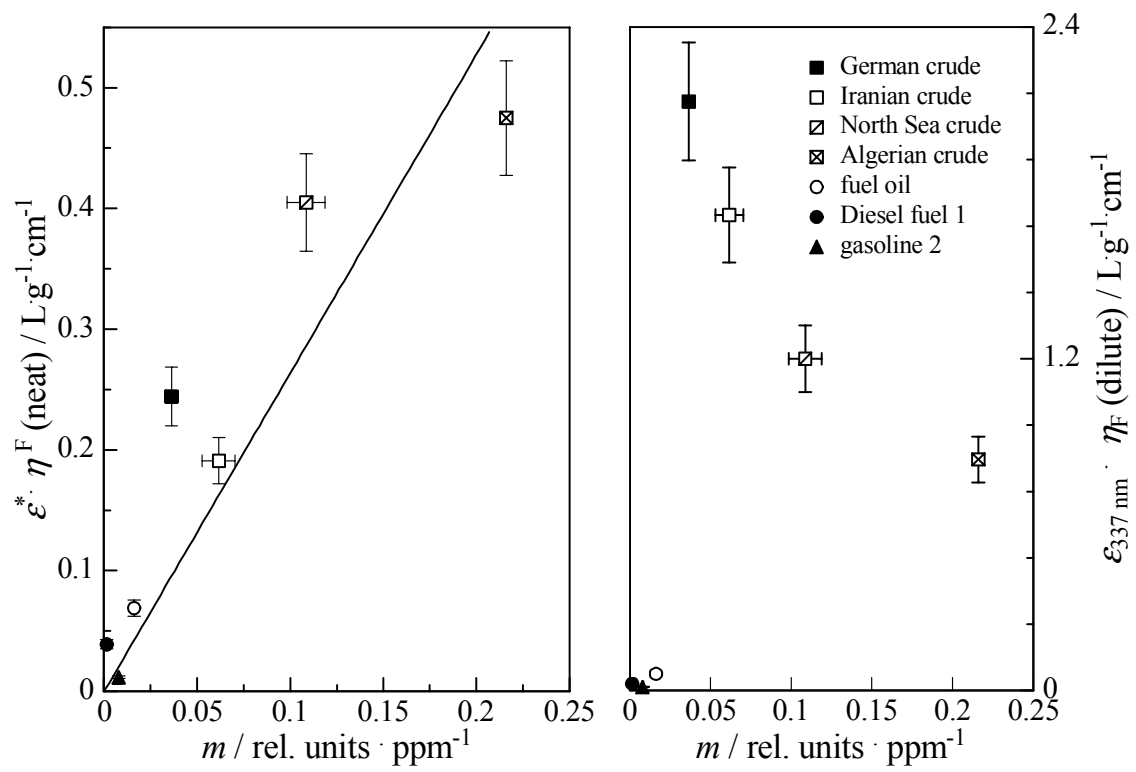

Fig. 5.8. Correlation of photophysical and calibration properties. Plots of the products of effective extinction coefficients and relative fluorescence efficiencies (both determined with the LIF demonstrator unit at $\lambda_{\mathrm{ex}}=337 \mathrm{~nm}$ ) for neat (left) and dilute (right) oils vs. the slopes of the quartz sand calibration functions measured with the OPTIMOS $\left(\lambda_{\mathrm{ex}}=355 \mathrm{~nm}\right)$. 


\subsubsection{LIF spectroscopic investigations of real-world soils}

In order to evaluate the potential of LIF spectroscopy in practice, two sets of realworld soils were investigated. First, the treated (dried and ground) soil samples were analyzed with the LIF demonstrator unit $\left(\lambda_{\text {ex }}=337 \mathrm{~nm}\right)$. Secondly, the untreated waste materials were investigated with the mobile LIF spectrometer OPTIMOS. All samples exhibited highly varying matrix properties, as was already evident from visual perception. In most cases the LIF spectra obtained from the real-world samples were broad and structureless with emission maxima around $450 \mathrm{~nm}$. Figure 5.9 shows comparisons of the results obtained by in situ LIF and ex situ IR analyses in double-logarithmic representations.
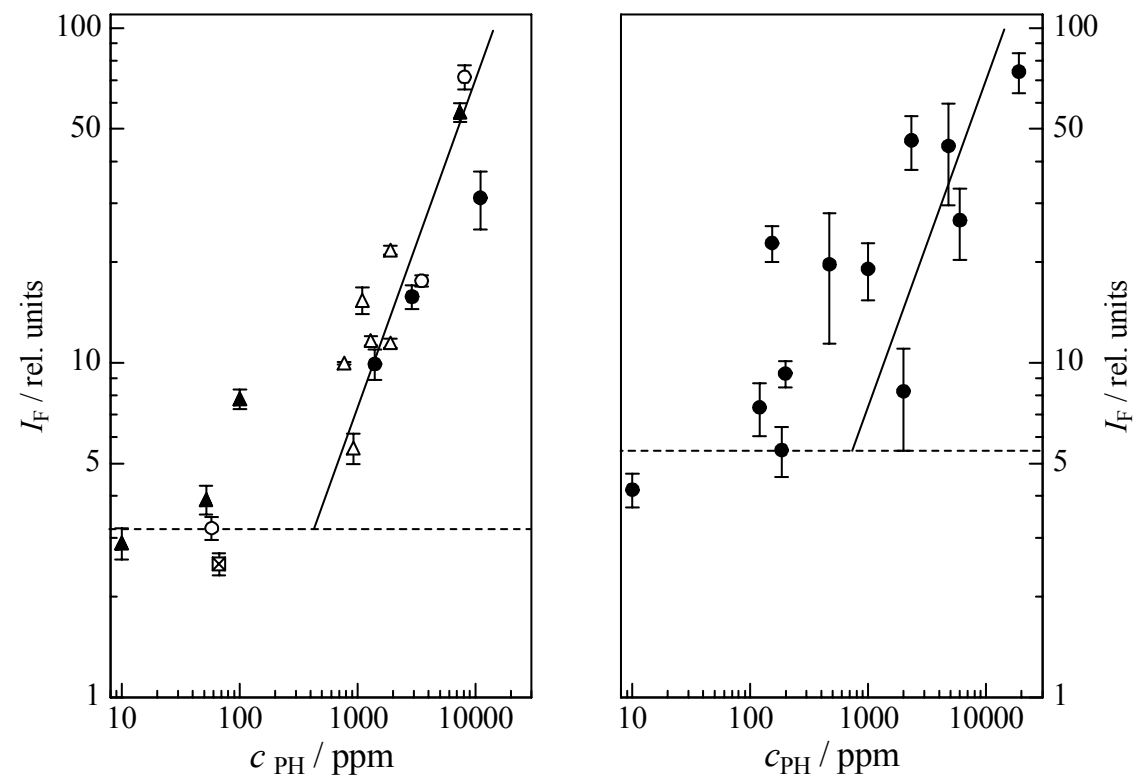

Fig. 5.9. Double-logarithmic representation of the LIF signal intensities vs. the results of the reference analysis for the dried and ground soil (left, uncorrected with respect to backscattered laser light) and untreated waste (right) samples. The approximate overall experimental uncertainties are illustrated by the dashed lines below which quantitative considerations are not possible. For the logarithms of the $I_{\mathrm{F}}$ and $c$ values, the solid lines have slope unity.

For the treated soils (left part) with TPH contents higher than 500 ppm a good correlation between $I_{\mathrm{F}}$ and TPH content is observed. The superimposed straight line with slope unity illustrates the concentration dependence of the LIF signal as expected from Equation 5.1. The data points scatter regularly around this line, which suggests that no systematic deviations occurred. The overall experimental uncertainties, mainly related to variations of background signals and reproducibil- 
ity problems, preclude a quantitative interpretation of LIF signals below the limits shown as dashed lines in Figure 5.9. This is in accordance with an estimated detection limit of ca. $100 \mathrm{ppm}$ for our LIF analysis of soils (Löhmannsröben 2000). The analogous plot of $I_{\mathrm{F}} \mathrm{vs.}$ TPH content for the waste materials (right part of Figure 5.9) clearly depicts enhanced deviations of the data points from the line with slope unity. However, the clear correlation between LIF signal intensity and degree of contamination is evident. It is emphasized that the waste materials were of very heterogenous nature, and would thus be difficult to characterize by any analytical technique. For us it was an important benchmark test that even under these difficult conditions for samples with TPH contents over ca. $1,000 \mathrm{ppm}$ a reliable in situ LIF analysis is feasible. We have previously shown that for different Diesel fuel-spiked LR soils with varying optical properties the LIF calibration behavior was improved by normalization with averaged values of the soils' diffuse reflectances $(R)$ in the spectral range of oil emission (Löhmannsröben 1999). This simple approach did not work for the realworld soils, i. e. did not improve the correlations shown in Figure 5.9. This is probably due to the fact that averaged $R$ values do not sufficiently describe the optical properties of these samples. Further investigations are under way to improve our understanding how optical properties of untreated real-world soils can be introduced into LIF calibration procedures.

\subsubsection{Field investigations}

We have performed field experiments at two different sites in southern Germany. All LIF data obtained were only interpreted qualitatively, i. e. no calibration was attempted. First, measurements were performed at a soil remediation plant in Roth (near Nürnberg) employing the LIF demonstrator unit. Soil remediation plants have a continuous demand for analytical investigations in order to control and optimize the remediation procedure. At the plant site various soil batches were examined, either by employing the fiber optical sensor head to investigate soils in buckets or by inserting the lancet into soil heaps. As an example, LIF spectra obtained from two soil charges in buckets, with measurements at three different surface positions each, are displayed in the left part of Figure 5.10. The upper traces show the LIF signals obtained directly from a contaminated soil at delivery, whereas the lower traces were from material after remediation. The rather slight variations of $I_{\mathrm{F}}$ at the three measurement positions indicate reasonable sample homogeneities. Subsequent laboratory analysis performed revealed that the TPH content of the soil at delivery was $2,100 \mathrm{ppm}$, whereas in the remediated material it was below $400 \mathrm{ppm}$. 

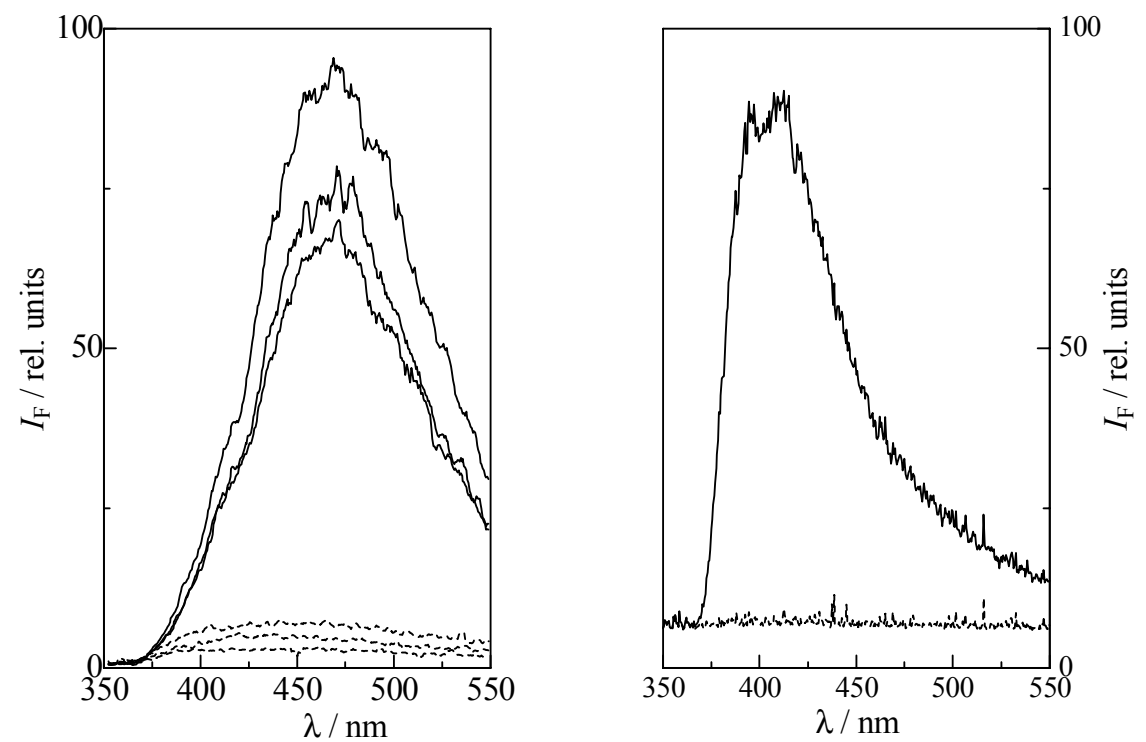

Fig. 5.10. LIF spectra obtained in field investigations at a soil remediation plant (left, LIF demonstrator unit, $\lambda_{\mathrm{ex}}=337 \mathrm{~nm}$ ) and a gravel pit (right, OPTIMOS, $\lambda_{\mathrm{ex}}=266 \mathrm{~nm}$ ).

In a second campaign measurements with the OPTIMOS spectrometer were performed at a gravel pit near Bamberg. It was suspected that in this pit slurries from paper recycling processes had been discharged and buried. For LIF measurements of subsurface profiles soil cores were brought up with a core barrel sampler and scanned along the rod with the fiber optical sensor head (Fig. 5.11). Shown in the right part of Figure 5.10 are LIF signals from two positions of such a core, namely from the surface (lower trace) and from ca. $50 \mathrm{~cm}$ depth (upper trace).

These results suggest an uncontaminated surface soil layer and the presence of fluorescent contamination underneath. We were thus able to predict a depth range of suspected high contamination. Based on these investigations the cores were sampled and high levels of contamination (up to TPH contents of 30,000 ppm) were later verified by laboratory analysis. 


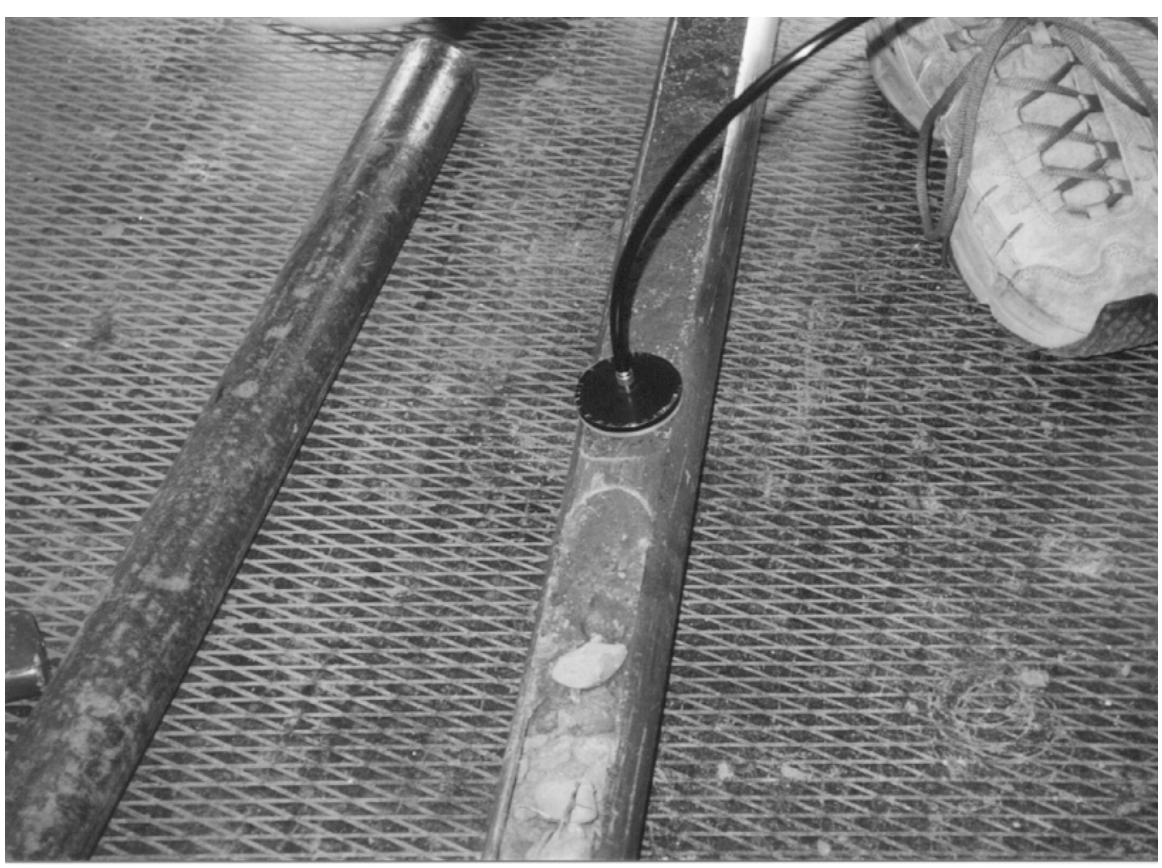

Fig. 5.11. Photograph of the core barrel sampler and the LIF sensor head used for scanning the soil core.

These examples demonstrate that in situ LIF analysis is a powerful method for on site screening investigations of contaminated soils. In soil remediation plants LIF measurements have promising potential for entrance and quality control. In combination with drilling techniques, in situ LIF is without competition for chemical analysis of organic pollutants in real-time subsurface characterization of contaminated sites, landfills etc. Undoubtedly, modern MWD ("measuring while drilling") concepts will increasingly make use of laser-based techniques.

\subsection{Conclusions}

Based on the photophysical characterization of the oils, the investigations of oilspiked LR materials provided information on the LIF calibration behavior. It was found that absorption and emission properties of the neat oils were the parameters relevant for detection sensitivity. The direct proportionality between the product $\left(\varepsilon^{*} \times \eta_{\mathrm{F}}\right)$ and the slopes $m$ of the calibration functions, as expected from fundamental considerations and as suggested by the results presented, e. g., in the left part of Figure 5.8, could have great practical advantages. Therefore the analysis of real-world contaminated soils is facilitated by solution-phase measurements of oils with appropriate photophysical properties. As an ultimate aim it can be envisaged 
965 Laser-Induced Fluorescence (LIF) Spectroscopy for the In Situ Analysis of Petroleum Product-Contaminated Soils

that the analytical parameters for in situ LIF analysis of various oils can thus be predicted and the number of necessary calibrations would be significantly reduced. With two exceptions, the oil detection limits determined ranged from 4 $23 \mathrm{ppm}$ for the crude oils on quartz sand to $500-600 \mathrm{ppm}$ for Diesel fuel 1 on quartz sand and fuel oil on the $A_{h}$ soil. Higher values were mainly due to excitation of reformates or distillates in spectral regions of too low absorbance. We feel confident that with optimized excitation conditions, detection limits of ca. $100 \mathrm{ppm}$ can be achieved for most oils on many soils. Of special interest are concentrations with regulatory relevance, as, e. g. contained in the so-called Dutch List for soil contaminants (Rosenkranz 1995). Herein, two values are given for petroleum products in soils: a reference concentration ( $R$ value) of $1,000 \mathrm{ppm}$, above which additional investigations of the soils are recommended, and an intervention concentration (I value) of $5,000 \mathrm{ppm}$, above which soil remediation is proposed. Evidently, the sensitivity achieved in the in situ LIF analysis of LR materials is fully sufficient to monitor these regulatory concentrations. For the realworld soil and waste samples, only qualitative LIF signal intensities $I_{\mathrm{F}}$ were recorded, i. e. no calibration attempt was made here. The clear correlation between $I_{\mathrm{F}}$ from in situ LIF measurements and the results of the ex situ reference analysis seems rewarding. Soil extraction and the quantification of petroleum products with the reference IR analysis is tedious and difficult. Round robin tests have shown that TPH contents reported by different laboratories have to be interpreted with caution (Fischer 1994, Heininger 1998). It is unclear to what extent the significant scatter of the data points in Figure 5.9 may be related to experimental uncertainties of the reference analysis. With in situ LIF investigation, disadvantages of sample pretreatment procedures can be avoided, and real-time, rapid and reliable soil analysis with high spatial resolution, even in subsurface measurements, can be performed. It is therefore expected that LIF measurements will acquire increasing importance for laboratory and on site soil analysis.

\section{Acknowledgment}

This work was financially supported by the Deutsche Bundesstiftung Umwelt (DBU, research programme OPTIMOS), the Bundesministerium für Bildung und Forschung (BMBF, research programme FLUTRAS), Bayern Innovativ and the University of Potsdam (Innovationsfond). For fruitful cooperation and support, thanks are due to Geosond GmbH, Bilfinger\&Berger AG, and Th. Hengstermann and F. Storck (both Optimare GmbH). 


\section{References}

Apitz SE, Borbridge LM, Theriault GA, Lieberman SH (1992) Remote in situ determination of fuel products in soils: field results and laboratory investigations. Analusis 20: 461-474

Balshaw-Biddle, K (ed.) (2000) Subsurface monitoring using laser fluorescence. Lewis Publishers, Boca Raton

Baumann T, Haaszio S, Niessner R (2000) Applications of a laser-induced fluorescence spectroscopy sensor in aquatic systems. Water Res. 34: 1318-1326

Fischer H, Kretschmar H-J, Christoph G, Neyen V (1994) Bestimmung von Mineralölkohlenwasserstoffen im Boden - Bodenstandards und Ringanalysen. Z. Umweltchem. Ökotox. 6: 189-195

Hart SJ, Chen Y-M, Kenny JE, Lien BK, Best TW (1997) Field demonstration of a multichannel fiber-optic laser-induced fluorescence system in a cone penetrometer vehicle. Field Anal. Chem. Technol. 1: 343-357

Heininger P, Pelzer J, Henrion R, Henrion G (1998) Results of a complex round robin test with four river sediments. Fresenius J. Anal. Chem. 360: 344-347

Illenseer C, Löhmannsröben H-G, Skrivanek Th, Zimmerman U (1999) Laser spectroscopy of humic substances. In: Understanding humic substances: advanced methods, properties and applications, Ghabbour EA, Davies G (eds.), Royal Society of Chemistry, London, 129-145

Lieberman SH, Inman SM, Theriault GA, Cooper SS, Malone PG, Lurk PW (1990) Fiber optic-based chemical sensors for in situ measurements of metals and aromatic organic compounds in seawater and soil systems. Proc. SPIE 1269: 175-184

Lieberman SH (1998) Direct-push, fluorescence-based sensor system for in-situ measurement of petroleum hydrocarbons in soils. Field Anal. Chem. Technol. 2: 63-73

Löhmannsröben H-G, Roch Th (1996) In-situ LIF analysis of polynuclear aromatic compounds (PAC) and mineral oils in soils. Proc. SPIE 2835: 128-134

Löhmannsröben H-G, Kauffmann C, Roch Th (1997) Spectroscopic properties of petroleum products in solution for in-situ analysis of oil contaminations. Proc. SPIE 3107: 305-314

Löhmannsröben H-G, Roch Th (1997) Laserfluoreszenzspektroskopie als extraktionsfreies Nachweisverfahren für PAK und Mineralöle in Bodenproben. In: Analytiker Taschenbuch, Springer-Verlag, Heidelberg, vol. 15, 217-253

Löhmannsröben H-G, Schober L (1999) Combination of laser-induced fluorescence and diffuse reflectance spectroscopy for the in situ analysis of Diesel fuel-contaminated soils. Applied Optics 38: 1404-1410

Löhmannsröben H.-G, Roch Th (2000) In situ laser-induced fluorescence (LIF) analysis of petroleum product-contaminated soil samples. J. Environ. Monit. 2: 17-22

Marowsky G, Lewitzka F, Bünting U, Niederkrüger M (2001) Quantitative analysis of aromatic compounds by laser induced fluorescence spectroscopy. Proc. SPIE 4205: $218-223$

Mullins OC, Zhu Y (1992) First observation of the Urbach tail in a multicomponent organic system. Appl. Spec. 46: 354-356

Mullins OC, Mitra-Kirtley S, Zhu Y (1992) The electronic absorption edge of petroleum. Appl. Spec 46: 1405-1411 
985 Laser-Induced Fluorescence (LIF) Spectroscopy for the In Situ Analysis of Petroleum Product-Contaminated Soils

Quinn MF, Al-Otaibi AS, Abdullah A, Sethi PS, Al-Bahrani F, Alameddine O (1995) Determination of intrinsic fluorescence lifetime parameters of crude oils using a laserfluorosensor with a streak camera detection system. Instrum. Sci. Technol. 23: 201-215

Ralston CY, Wu X, Mullins OC (1996) Quantum yields of crude oils. Appl. Spec50: 15631568

Rosenkranz D, Einsele G, Harreß H-M (1995) Bodenschutz. E. Schmidt Verlag, Berlin, vol. $2,1-4$

Schade W, Bublitz J (1996) On-site laser probe for the detection of petroleum products in water and soil. Environ. Sci. Technol. 30: 1451-1458

Shouse B (2001) Kuwait unveils plan to treat festering desert wound. Science 293: 1410

Wang X, Mullins OC (1994) Fluorescence lifetime studies of crude oils. Appl. Spec. 48: 977-984

Zimmermann B, Lucht H (1997) Field measuring devices for in-situ analysis of fluorescence contaminants in water and soil. In: Field Screening Europe, Gottlieb J. (ed.), Kluwer Academic Publishers, Dordrecht, 381-384 